DOI: 10.14451/1.171.84

\title{
ВЛИЯНИЕ СОЦИАЛЬНО-ЭКОНОМИЧЕСКИХ ФАКТОРОВ НА ПРОЦЕСС ВОСПРОИЗВОДСТВА ТРУДОВЫХ РЕСУРСОВ В СЕЛЬСКОМ ХОЗЯЙСТВЕ АЛТАЙСКОГО КРАЯ
}

\author{
(c) 2019 Беляев Виктор Иванович \\ доктор экономических наук, профессор \\ Алтайский государственный университет \\ 656049, г. Барнаул, проспект Ленина, 61 \\ E-mail: belyaevvi@mail.ru
}

(c) 2019 Кудинова Маргарита Геннадьевна

кандидат экономических наук, доцент, зав. кафедрой финансов, бухгалтерского учета и аудита Алтайский государственный аграрный университет

656049, г. Барнаул, проспект Красноармейский, 98

E-mail: kudinova_margarita@mail.ru

(C) 2019 Федулова Инна Владимировна

кандидат экономических наук, доцент, кафедра финансов, бухгалтерского учета и аудита

Алтайский государственный аграрный университет

656049, г. Барнаул, проспект Красноармейский, 98

E-mail: fedulova_innavl@mail.ru

(c) 2019 Безгодова Ольга Игоревна аспирант

Алтайский государственный университет

656049, г. Барнаул, проспект Ленина, 61

E-mail: bezgodova.olenka@mail.ru

(c) 2019 Кудинов Богдан Дмитриевич

Алтайский государственный аграрный университет

656049, г. Барнаул, проспект Красноармейский, 98

E-mail: kudinov_bogdan@mail.ru

На сегодняшний день сложилась довольно негативная ситуация с воспроизводством трудовых ресурсов в большинстве районов Алтайского края. Этот факт оказывает значительное влияние на производительность труда, а, следовательно, и на все основные социально-экономические показатели сельскохозяйственного производства. Значительно ограничивает возможности дальнейшего устойчивого развития АПК региона.

Ключевые слова: рынок труда, трудовые ресурсы, сельское хозяйство, производительность, воспроизводство, кадровое обеспечение.

Введение. Ни для кого не секрет сложность сегодняшнего положения населения России в селах. Социально-экономические изменения последних десятилетий в стране коренным образом трансформировали реалии воспроизводства трудовых ресурсов в сельском хозяйстве. При проведении реформ не были учтены характерные черты менталитета сельского населения, которое было не способно за короткое время приспособиться к резко меняющимся рыночным условиям, что, в значительной мере, привело к спаду производства.
При этом, в настоящее время вследствие падения размеров производства, снижения социально-экономических условий, ухудшения демографической ситуации произошло не неутешительны только абсолютное снижение количества занятых в сельхозпроизводстве в общем и целом, снижение количества трудящихся квалифицированных кадров, но также снижался их качественный состав и профессиональный уровень, остро выявился их недостаток.

Цель исследования. Повышение эффективности сельского хозяйства зачастую определя- 
ется обеспеченностью аграрного сектора трудовыми ресурсами с высокими показателями общей культуры, профессионализма, общечеловеческой, экономической и правовой грамотности, владеющими новыми технологиями и имеющими возможность применять их в производстве. Все это свидетельствует о том, что для достижения хорошего положения в экономики и перспективы роста нужно преобразовывать социально-трудовые отношения. Отстранение государства от регулирования социальной сферы в большой мере ухудшило положение в сельской местности. Введение закона «О занятости населения в РФ» привело к необходимости пересмотра процесса воспроизводства кадров в современных социально-экономических условиях, введения новых методов управления формированием трудовых ресурсов. В этой связи возникла необходимость системы оценки социально-экономических условий формирования и воспроизводства трудовых ресурсов и изыскания средств дальнейшего их эффективного их использования.

Результаты. Алтайский край - житница не только Сибири, но и страны в целом. Регион является крупнейшим производителем зерна в Российской Федерации. Край располагает высоким потенциалом в области производства сельскохозяйственной продукции. Общая площадь земель сельскохозяйственного назначения составляет 11,6 миллиона гектаров, в том числе сельскохозяйственных угодий - 10,6 миллиона гектаров, из них пашни - 6,5 миллиона гектаров - это самая большая площадь пашни среди регионов Российской Федерации. Занимая лишь $4 \%$ территории и имея около $12 \%$ населения Сибири, край производит пятую часть сельскохозяйственной продукции Сибирского федерального округа.

В общем объеме реализованной сельскохозяйственной продукции доля растениеводческой продукции составляет около 45\%. Посевные площади сельскохозяйственных культур во всех категориях хозяйств ежегодно занимают 5,4-5,5 млн. гектаров, в том числе зерновые и зернобобовые культуры до 3,8 млн. гектаров, технические - более 620 тыс. гектаров. Свыше 1 млн. гектаров ежегодно занимают кормовые культуры.

По объёмам производства зерна и, в первую очередь, высококачественной пшеницы, край входит в первую пятёрку регионов страны, а зерновое поле Алтая самое большое в России. Здесь производится в пределах 40\% зерна от общего сибирского объема. В 2017 году валовой сбор зерна в Алтайском крае составил 5 млн. 390 тыс. тонн. В крае выращиваются озимые и яровые зерновые культуры. Доля яровых культур составляет 96\% от общей посевной площади зерновых, озимых (пшеница и рожь) - 4\%.

Основным направлением использования произведенного в крае зерна является выработка муки, круп местными перерабатывающими предприятиями. Ежегодно в Алтайском крае производится свыше 1,2 млн. тонн. муки, 230 тыс. тонн крупы и 400 тыс. тонн комбикормов. Каждая восьмая тонна муки и каждая пятая тонна крупы, производимая в России - алтайская.

Алтайский край - крупнейший производитель маслосемян подсолнечника в Сибирском федеральном округе, на его долю приходится около 90\% производства. В 2017 году его произведено 599 тыс. тонн. Имеющиеся мощности позволяют перерабатывать на масло практически весь производимый объём сырья. В Алтайском крае выращивается такая ценная масличная культура как рапс яровой. В Алтайском крае за последние годы площадь посева рапса увеличилась в 1,5 раза. В 2017 году в регионе его валовой производство в 1,6 раза превысило показатели 2016 года и составило 78 тыс. тонн маслосемян рапса.

Животноводство - структурообразующая и социально значимая отрасль сельского хозяйства Алтайского края. Оно представлено подотраслями: молочное и мясное скотоводство, свиноводство, птицеводство, коневодство, овцеводство, пантовое оленеводство, пчеловодство, звероводство и рыбоводство.

На 1 января 2018 года поголовье крупного рогатого скота составило 810,2 тыс. голов, в том числе коров - 341,9 тыс. голов; свиней - 561,1 тыс. голов, овец и коз - 257,4 тыс. голов. За 2017 год в хозяйствах всех категорий объем производства молока составил 1 млн. 401,8 тыс. тонн, скота и птицы на убой (в живом весе) произведено 308,7 тыс. тонн. В крае получено 1 млрд. 114 млн. яиц. Производством молока в регионе занимаются более 430 хозяйств. В рейтинге регионов России край входит в тройку лидеров по объемам производства молока и высококачественной говядины.

Алтайский край является одним из немногих регионов России, аграрный потенциал которого 
позволяет в полном объеме обеспечить внутренний спрос практически на все основные виды продовольственной продукции, за исключением теплолюбивых сельскохозяйственных культур (бахчевых, фруктов). Ресурсы регионального продовольственного рынка формируются, главным образом, за счет продукции собственного производства, что обеспечивает высокий уровень продовольственной независимости региона. За последние пять лет в Алтайском крае в расчете на душу населения произведено в среднем 1,8 тонн зерна, что в 1,8 раза выше необходимого для обеспечения продовольственной безопасности объема и в 2,4 раза выше, чем в среднем по Российской Федерации. В расчете на душу населения в 2017 году произведено около 595 кг молока, 95 кг мяса (или 130,9 кг скота и птицы на убой в живом весе), 473 шт. яиц, более 2,1 тонн зерна, 365 кг картофеля и 98 кг овощей и продовольственных бахчевых культур.

Вместе с тем, кадровое обеспечение аграрного производства Алтайского края недостаточное.

По итогам 2017 года целевое значение указанного показателя не выполнено в 29 районах края. Наиболее низкий уровень показателя отмечен в Тюменцевском (отклонение фактического значения показателя от планового составляет -18,1 п.п.), Угловском (-14,3 п.п.), Панкрушихинском (-14,2 п.п.), Крутихинском (-10,0 п.п.), Ключевском (-9,5 п.п.), Змеиногорском (-7,2 п.П.), УстьПристанском (-6,8 п.п.), Курьинском $(-6,4$ п.п.), Солтонском (-6,0 п.п.), Ельцовском $(-5,4$ п.п.), Локтевском (-5,2 п.п.) районах.

Несмотря на серьезную государственную поддержку по привлечению и закреплению специалистов на селе, кадровая ситуация в аграрном секторе экономики Алтайского края остается достаточно напряженной. Сохраняется тенденция роста удельного веса работников руководящего состава старше пенсионного возраста при одновременном снижении доли в возрасте до 30 лет. Продолжается динамика снижения доли молодежи и среди рабочих кадров.

Серьезной проблемой остается проблема восполнения аграрной отрасли молодыми специалистами из-за низкого показателя трудоустройства выпускников вузов и профессиональных образовательных организаций в АПК. В 2017 году трудоустроились в сельскохозяйственные организации края чуть более 100 молодых специалистов с высшим образованием (15\% от их выпуска). Показатель трудоустройства выпускников профессиональных образовательных организаций, окончивших курс обучения по программам подготовки специалистов среднего звена, составил 3,3\%, по программам подготовки квалифицированных рабочих и служащих только 2,7\%.

На закрепление высококвалифицированных специалистов в отрасли негативно влияют бытовая неустроенность и неразвитость социальной инфраструктуры сельских территорий, непопулярность сельскохозяйственного труда у молодежи, а также низкая материальная мотивация их к работе на селе. Не способствуют улучшению кадровой ситуации, существующие в действующем законодательстве, ограничения для предприятий АПК всех организационно-правовых форм по использованию механизма целевой подготовки специалистов на условиях целевого приема за счет средств федерального бюджета. Решение проблемы развития и укрепления

Таблица. Динамика показателей кадрового обеспечения аграрного сектора АПК Алтайского края

\begin{tabular}{|l|c|c|c|}
\hline \multicolumn{1}{|c|}{ Показатели } & 2015 г. & 2016 г. & 2017 г. \\
\hline Обеспеченность отрасти всеми категориями работников, \% & 95,1 & 93,7 & 93,5 \\
\hline Обеспеченность руководителями и специлистами всех уровней, всего, \% & 93,8 & 92,5 & 93,1 \\
\hline Доля руководителей и специалистов, имеющих высшее образования, \% & 37,8 & 39,4 & 40,1 \\
\hline $\begin{array}{l}\text { Доля руководителей и специалистов в возрасте 55 лет - женщин } \\
\text { и б0 лет - мужчин, \% }\end{array}$ & 11,4 & 12,3 & 12,4 \\
\hline Число вакантных должностей руководителей и специалистов, ед. & 6259 & 725 & 646 \\
\hline $\begin{array}{l}\text { Обеспеченность сельскохозяйственных организаций кадрами рабочих } \\
\text { массовых профессий, всего, \% }\end{array}$ & 95,4 & 94,1 & 93,6 \\
\hline Число вакантных должностей на рабочие должности, ед. & 1823 & 2255 & 2245 \\
\hline $\begin{array}{l}\text { Обеспеченность сельскохозяйственных организаций трактористами- } \\
\text { машинистами, \% }\end{array}$ & 92,1 & 92,0 & 91,9 \\
\hline Доля трактористов-машинистов в возрасте до 30 лет, \% & 13,3 & 12,4 & 11,1 \\
\hline Доля трактористов-машинистов в возрасте свыше 60 лет, \% & 5,2 & 5,1 & 4,9 \\
\hline
\end{tabular}


кадрового потенциала агропромышленного комплекса края требует расширения перечня и усиления мер государственной поддержки, продолжения совершенствования форм работы, создания условий для развития аграрного сектора региона и сельских территорий, что позволит повысить привлекательность работы и проживания в сельской местности. В решении этих задач необходима консолидация усилий и активизация действий всех заинтересованных сторон, в том числе муниципальных органов власти, руководителей организаций АПК и образовательных учреждений.

При определении потребности в трудовых ресурсах обнаруживается необходимость повышенного внимания к проблемам всестороннего учета динамики инновационных изменений в экономике народного хозяйства, отдельных отраслей и регионов, к вопросам диверсификации производства, позволяющей более полно использовать разнообразие трудовых ресурсов.

Для регионов формирование комплексной ресурсной базы воспроизводства приобретает свою специфику по целому ряду причин, обусловленных системой источников, формами и видами ресурсов и их оптимальной сочетаемостью, конкретным комплексом приоритетов в социально-экономическом развитии субъектов РФ, факторами ее развития в динамике в современных условиях рынка, а также ограниченностью стадий воспроизводства и особенностями ресурсных воспроизводственных циклов.

Обсуждение. В процессе исследования обращено внимание на то, что закономерности воспроизводства трудовых ресурсов имеют свои особенности в условиях организации рыночных отношений, которые проявляются, прежде всего, во-первых, в том, что ориентация предпринимательской деятельности на всемерное увеличение прибыли не может не сопровождаться определенным сокращением спроса на рабочую силу не только благодаря повышению производительности труда, но и за счет роста интенсивности производства, сопровождающегося нерациональным использованием рабочей силы.

Во-вторых, развитие рынка труда содействует тому, что в целях повышения конкурентоспособности рабочей силы, с одной стороны, обеспечивает качественный рост функционирования рабочей силы, повышение ее производительности, а с другой - ведет к деградации трудовых ресурсов в составе армии безработных.
B-третьих, рост дифференциации населения по уровню доходов становится фактором развития элитарного, в значительной мере паразитарного спроса, что вызывает необходимость перемещения части трудовых ресурсов в непроизводственную сферу, увеличивая тем самым непроизводительные издержки.

На реализацию программных мероприятий по повышению кадрового потенциала АПК края в 2017 году из регионального бюджета направлено около 53,0 млн. рублей, что на уровне 2016 года. В целях пополнения руководящего корпуса предприятий АПК высококвалифицированными кадрами и расширения доступа сельской молодежи к получению профессионального образования в учебных заведениях аграрного профиля, на системной основе проводилась работа по подготовке на целевой основе в ФГБОУ ВО «Алтайский государственный аграрный университет» (Алтайский ГАУ). В ее рамках совместно с Алтайский ГАУ проводился отбор студентов, мотивированных на работу в отрасли, организовано взаимодействие организаций АПК со студентами и Алтайским ГАУ, проводилась разносторонняя разъяснительная работа о механизмах организации и государственной поддержки целевой подготовки. Несмотря на проводимую масштабную работу по разъяснению преимуществ механизма целевой подготовки кадров и его поддержки за счет средств краевого бюджета, далеко не все имеющие кадровый дефицит предприятия использовали этот механизм для его восполнения.

В целях закрепления специалистов в организациях АПК Алтайского края в 2017 году 43 молодым специалистам из краевого бюджета направлено 5,8 млн. рублей государственной поддержки в виде социальной выплаты на обустройство и хозяйственное обзаведение.

Реализация комплекса мер по поддержке развития кадрового потенциала АПК Алтайского края, включая мероприятия по социальному развитию села, позволила приостановить тенденцию роста дефицита кадров организаций сельскохозяйственной отрасли региона и прироста рабочих кадров старше пенсионного возраста, сохранить динамику повышения качественного состава руководящего корпуса, удержать наметившуюся динамику роста уровня обеспеченности хозяйств руководителями и специалистами всех категорий.

В 2017 году в сравнении с 2016 годом удель- 
ный вес кадров руководящего состава с высшим образованием увеличился на 0,7 п.п., в том числе главных специалистов на 1,4 п.п., специалистов среднего звена - на 0,5 п.п. (рисунок).

Несмотря на положительную динамику ряда показателей по развитию кадрового потенциала Алтайского края, остаются актуальными проблемы обеспечения АПК кадрами рабочих массовых профессий. По состоянию на 01.01.2018 года показатель обеспеченности сельскохозяйственных организаций рабочими кадрами, постоянно работающими в сельскохозяйственном производстве, снизился к уровню предыдущего года на 0,5 п.п. В отрасли сохраняется недостаток кадров всех категорий работников. В сельскохозяйственных организациях края всех форм собственности остаются вакантными 2891 рабочее место, в том числе 646 - на должности руководящего состава, из них 175 мест - на должности главных специалистов. Наблюдается дефицит специалистов всех уровней агрономических, ветеринарных, зоотехнических, технических и учетно-финансовых служб. Хозяйства края испытывают потребность в трактористах-машинистах, операторах машинного доения и других категориях рабочих.

Результаты. Проведенный анализ состояния проблемы влияния социально-экономических факторов на воспроизводство трудовых ресурсов в сельском хозяйстве дает возможность сделать следующие главные выводы:

В последние несколько десятилетий в аграрном секторе идет процесс снижение показателей трудовых ресурсов, как по количеству, так и по состоянию их качества. Данное положение, характеризуется главным образом уменьшением доходов людей и снижением социальной инфра- структуры в сельской местности, отсутствием экономических приемов воспроизводства трудовых ресурсов. Главным и наиболее болезненным показателей, показывающим снижение условий воспроизводства трудовых ресурсов стал уровень оплаты труда. Для того, чтобы максимально реально оценить действительную ситуацию, необходимо разработать методику, которая бы могла показать направление снижения доходов населения сельской местности, учитывая при этом происходящее некоторое увеличение номинальной заработной платы. Уменьшение реальной заработной платы становится главной причиной, снижения обеспеченности сельского хозяйства страны трудовыми ресурсами, как по количеству, так и по состоянию качества.

Особенность сельского хозяйства состоит в том, что здесь формирование трудовых ресурсов происходит под воздействием множества факторов, которые можно разделить на три основные группы: экономические, социальные и демографические. Эти факторы, различны по содержанию и эффективности воздействия, что позволило нам в процессе их изучения и обобщения составить следующую схему классификации.

Вместе с тем, наибольшее значение на формирование трудовых ресурсов оказывают экономические условия. Причем не просто уровень заработной платы в конкретной отрасли, а ее соотношение с другими отраслями экономики и прожиточным минимумом.

В предложенной нами системе в группу экономических факторов, кроме уровня доходов и безработицы должны быть отнесены ресурсы производства, которые тоже непосредственно влияют на формирование трудовых ресурсов.

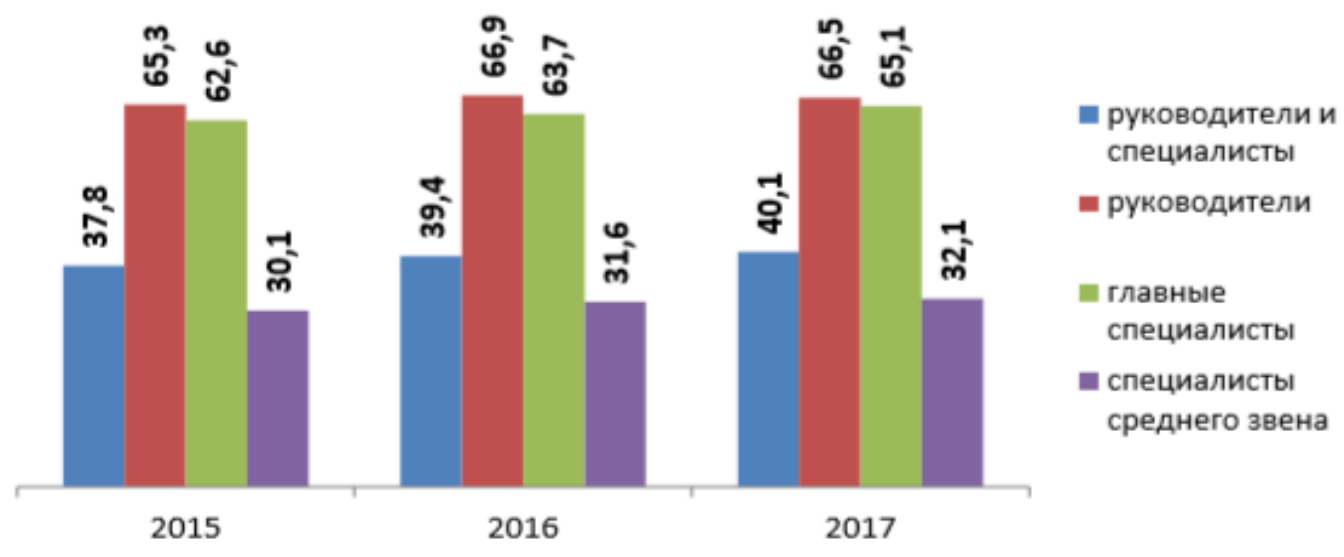

Рис. Доля руководителей активности и специалистов неутешительны с высшим показатели образованием, в призваны общем их спецификации числе,\% 
Однако это не уменьшает значение других групп факторов, особенно социальной инфраструктуры села.

Социологические исследования показали, что уровень трудообеспеченности во многом определяется обеспеченностью жильем, качественным медицинским обслуживанием, наличием учреждений образования и объектов социально-культурного назначения, газификацией населенных пунктов и наличием асфальтированных дорог. Улучшение социальных и экономических условий ведет к увеличению рождаемости и уменьшению оттока людей из сельской местности [1].

Социально-экономическим факторам присущи большие возможности эффективного вли- яния на результаты экономики, так как повышение условий жизни, улучшения всей социальной сферы развивают хорошие условия для создания трудовых ресурсов и их производительности труда. Поэтому возникает необходимость разработки экономического механизма управления данными факторами, а также важно в нормативном порядке обеспечить приоритетность социального формирования села финансовой, экономической, инвестиционной, правовой и социальной политикой.

Разработанные направления позволят улучшить структуру трудовых ресурсов сельского хозяйства и могут найти эффективное применение и в Алтайском крае и других регионах, а также в стране в целом.

\section{Библиографический список}

1. Акмаров П.Б., Горбушина Н.В. Особенности формирования трудовых ресурсов сельского хозяйства в трансформационной экономике. Ижевск: 2006. 104c.

2. Борисов А.Б. Большой экономический словарь. Москва.2003. 895 с.

3. Вознюк E. А. Трудовые ресурсы как социально-экономический фактор, влияющий на результаты деятельности сельского хозяйства (на примере ГАОУ СПО «Оренбургский аграрный колледж») // Молодой ученый. 2016. № 3. C. 423-426. URL https://moluch.ru/archive/107/25191/ (дата обращения: 03.12.2018).

4. Горбушина Н.В. Комплексная оценка условий формирования трудовых ресурсов в сельском хозяйстве.// Материалы межрегиональной научно-практической конференции “Молодые ученые сельскому хозяйству России”. Оренбург. 2005. С.131-133 (0,1 п.л.).

5. Экономика от А до Я. Тематический справочник /Под ред. Г. М. Гукасьян. Москва. 2007. 480 с.

6. Доклад о ходе и результатах реализации в 2017 году государственных программ в сфере развития сельского хозяйства Алтайского края [Электронный ресурс]. Режим доступа: https://cloclo41.datacloudmail.ru/weblink/ view/CbjQ/YVUMpY1nA?etag=F4C6F759CE4D3EC234AC88BC1C856BAC73788905\&key=0754020f99e08f5a60c3 01c5f2c401a3adf274f1 